\title{
REVIEW
}

\section{Atypical pathogens and respiratory tract infections}

\author{
F. Blasi
}

Atypical pathogens and respiratory tract infections. F. Blasi. (C) ERS Journals Ltd 2004 ABSTRACT: The atypical respiratory pathogens Chlamydia pneumoniae, Mycoplasma pneumoniae and Legionella pneumophila are now recognised as a significant cause of acute respiratory-tract infections, implicated in community-acquired pneumonia, acute exacerbations of chronic bronchitis, asthma, and less frequently, upper respiratory-tract infections.

Chronic infection with $C$. pneumoniae is common among patients with chronic obstructive pulmonary disease and may also play a role in the natural history of asthma, including exacerbations. The lack of a gold standard for diagnosis of these pathogens still handicaps the current understanding of their true prevalence and role in the pathogenesis of acute and chronic respiratory infections.

While molecular diagnostic techniques, such as polymerase chain reaction, offer improvements in sensitivity, specificity and rapidity over culture and serology, the need remains for a consistent and reproducible diagnostic technique, available to all microbiology laboratories.

Current treatment guidelines for community-acquired pneumonia recognise the importance of atypical respiratory pathogens in its aetiology, for which macrolides are considered suitable first-line agents. The value of atypical coverage in antibiotic therapy for acute exacerbations of chronic bronchitis and exacerbations of asthma is less clear, while there is no evidence to suggest that atypical pathogens should be covered in antibiotic treatment of upper respiratory-tract infections.

Eur Respir J 2004; 24: 171-181.
Institute of Respiratory Diseases, University of Milan, IRCCS Ospedale Maggiore, Milan, Italy.

\section{Correspondence: F. Blasi}

Istituto di Tisiologia e Malattie dell'Apparato Respiratorio

Universita degli Studi Milano

Pad. Litta

IRCCS Ospedale Maggiore di Milano

Via F. Sforza 35

20122 Milano

Italy

Fax: 390250320628

E-mail: francesco.blasi@unimi.it

Keywords: Atypical

Chlamydia

Legionella

Mycoplasma

respiratory-tract infections

Received: December 82003

Accepted after revision: February 232004
The term "atypical pathogen" most commonly refers to Chlamydia pneumoniae, Mycoplasma pneumoniae and Legionella pneumophila. Once believed to be of little clinical significance, a wealth of data accumulated over the past decade suggests that these are important respiratory pathogens in a wide range of respiratory-tract infections (RTIs) and are capable of causing severe, as well as mild-to-moderate, illness.

Although the role of atypical pathogens [1], and of $C$. pneumoniae in particular [2], has been reviewed previously, there has been little focus on appropriate coverage of these pathogens in treatment decisions for patients with RTIs. In addressing this issue, this review examines the role of atypical pathogens in the aetiology of upper and lower RTIs, in both adults and children, and discusses the value of appropriate coverage of these pathogens in empirical antibiotic prescribing.

\section{Organisms}

\section{Chlamydia pneumoniae}

C. pneumoniae, an obligate intracellular bacteria, was first recognised as a respiratory pathogen in 1986 [3] (fig. 1). It was originally known as TWAR; a name derived from the first $C$. pneumoniae isolate TW-183 ${ }^{\mathrm{T}}$, obtained in 1965 from a conjunctival swab, and AR-39, the first pharyngeal isolate [4].

Since its identification in the late 1980s, C. pneumoniae has emerged as the most common nonviral intracellular human respiratory pathogen [5-7] and an important cause of acute and chronic infection of the upper and lower respiratory tract in both immunocompetent and immunocompromised hosts [5]. Among patients with community-acquired pneumonia (CAP), $C$. pneumoniae is one of the more common aetiological agents [1].

Legionella pneumophila

Legionellae are intracellular Gram-negative, aerobic bacilli that can replicate in respiratory monocytic cells. At least 48

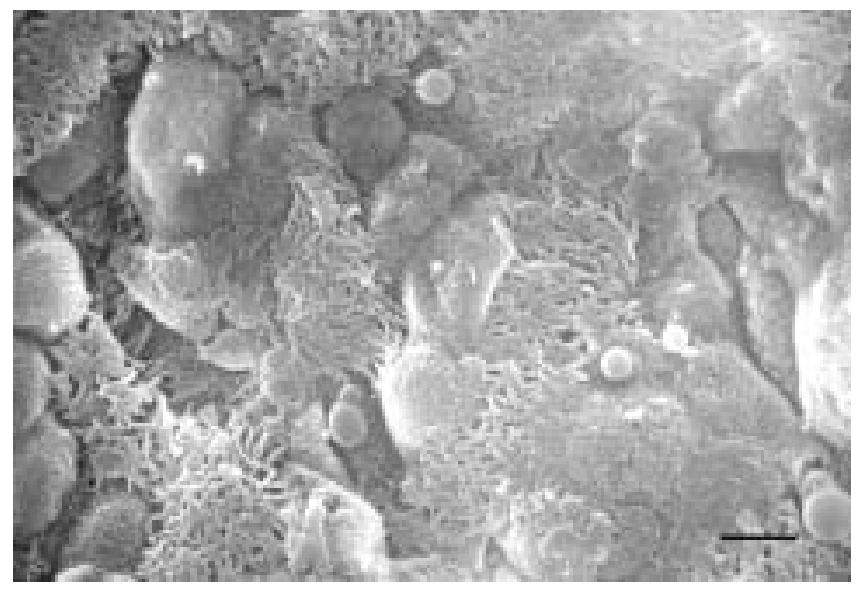

Fig. 1.-Scanning electron microscopy of the epithelial layer of the trachea from mice after infection with Chlamydia pneumoniae. Scale bar $=10 \mu \mathrm{m}$. 
species of Legionella, comprising 70 distinct serogroups, have been identified, of which L. pneumophila is responsible for the majority of cases of legionellosis, the clinical syndrome associated with Legionella sp. infection [8]. Legionellosis consists of two distinct clinical entities: Legionnaire's disease, a severe and potentially fatal form of pneumonia, and Pontiac fever, a self-limiting acute febrile illness [8].

Legionnaire's disease was first described in 1977, following a major outbreak of pneumonia among members of the American Legion attending a convention in Philadelphia the previous year [9]. It has since been recognised as an important aetiological agent of CAP, responsible for both sporadic and large-scale outbreaks [8].

\section{Mycoplasma pneumoniae}

As the first of the atypical pathogens to be identified as a cause of RTI, for many years $M$. pneumoniae was known as the Eaton agent, after EATON et al. [10] identified this pleuropneumonia-like organism from the sputum of patients with "primary atypical pneumonia" in 1944. It was subsequently renamed $M$. pneumoniae and identified as a common cause of respiratory disease in man [11]. Of the many species of Mycoplasma known to infect man, M. pneumoniae is the only one that causes RTIs [12].

\section{Identification}

For the majority of RTIs, an aetiological diagnosis is never established. In the case of lower RTIs, sputum, and to a lesser extent pleural fluid and bronchoalveolar aspirates, are often contaminated with indigenous bacterial flora. Furthermore, once a sample has been collected, the laboratory tests are often slow, insensitive and laborious. This is especially true with the identification of atypical intracellular pathogens, for which culture and serology have traditionally been employed for diagnosis. Similarly, in the case of upper RTIs, swab samples are often contaminated. Other diagnostic techniques, such as tympanocentesis, may not always be appropriate for paediatric patients or in the outpatient setting.

The variable sensitivity and specificity of currently available tests make diagnosis of an acute infection unreliable, and compromise the reliability of prevalence data based on paired sera. Diagnosis protocols developed in the research laboratory may not translate well to clinical practice, where clinical samples from the patient population are much more diverse, and where financial support and technology may not be comparable [13]. In addition, species such as $C$. pneumoniae have emerged relatively recently as an important cause of RTI and were not investigated until a short time ago.

Nonetheless, as the recent guidelines from the Infectious Disease Society of America (IDSA) have emphasised, an aetiological diagnosis can be useful for prognostic and therapeutic purposes, as well as advancing current knowledge of epidemiologically important pathogens [14]. A definitive diagnosis for example, allows antibiotic therapy to be targeted against particular pathogens, rather than being purely based on empirical selection. This has implications for infections due to the intracellular atypical respiratory pathogens Chlamydia and Legionella, and for Mycoplasma, which lacks a conventional cell wall and is thereby refractory to treatment with $\beta$-lactam antibiotics. Penicillins and cephalosporins are also unable to penetrate inside cells, a prerequisite for efficacy against obligate intracellular pathogens, such as C. pneumoniae and L. pneumophila.

However, new techniques are emerging with the promise of more rapid and reliable identification of atypical pathogens. A microimmunofluorescence assay for the identification of C. pneumoniae infection has shown that the antibody response to an acute primary infection is characterised by a rise in immunoglobulin ( $\mathrm{Ig}) \mathrm{M}$ titre, followed by increases in $\mathrm{IgG}$, whereas in cases of re-infection, only $\operatorname{IgG}$ and $\mathrm{IgA}$ antibody titres increase. Within 2-3 months of an acute infection, IgM levels are no longer detectable, but persistent levels of $\operatorname{IgG}$ and IgA antibody suggest evidence of persistent or chronic C. pneumoniae infection [5].

Molecular techniques, such as polymerase chain reaction (PCR), hold more promise for diagnosis, and may offer advantages in rapidity, sensitivity and specificity over conventional culture and serology [13]. The technique has already been successfully applied to the rapid identification of $C$. pneumoniae, M. pneumoniae and L. pneumophila in respiratory secretions [13]. However, while PCR is emerging as one of the most accurate methods for the rapid identification of atypical respiratory pathogens, much work remains in developing PCR assays that can be readily adopted by routine diagnostic laboratories [13]. Unlike microbiological testing, diagnosis with PCR has a limited ability to test antimicrobial susceptibility and does not provide an isolate archive, should further testing be necessary. Also, reproducibility may be difficult to achieve outside the research laboratory, since clinical samples are frequently from diverse patient populations, necessitating adjustment of PCR protocols with regard to sample preparation and amplification conditions. Furthermore, positive results may not distinguish between colonisation and infection [13].

\section{In vitro susceptibility}

Although the $\beta$-lactams are ineffective against atypical respiratory pathogens, several classes of commonly used antibiotics possess in vitro activity against $C$. pneumoniae, $M$. pneumoniae and L. pneumophila, including the macrolides, fluoroquinolones, tetracyclines and ketolides.

Macrolides exhibit excellent in vitro activity against atypical respiratory pathogens, and have traditionally been considered drugs of first choice for infections due to atypical pathogens [15-23]. Against contemporary isolates of C. pneumoniae, the minimum inhibitory concentration minimal inhibitory concentration of $90 \%$ bacteria values of the macrolides (erythromycin, roxithromycin, clarithromycin and azithromycin) are typically in the range of $0.016-0.5 \mathrm{mg} \cdot \mathrm{L}^{-1}[15,21,22,24,25]$. Macrolides are especially potent against strains of $M$. pneumoniae, with recent studies showing MIC90 values of $0.0019,0.0019$ and $0.0039 \mathrm{mg} \cdot \mathrm{L}^{-1}$ for erythromycin, clarithromycin and roxithromycin respectively [19], and of $<0.0005 \mathrm{mg} \cdot \mathrm{L}^{-1}$ for azithromycin [15]. The newer macrolides tend to exhibit greater in vitro activity against $L$. pneumophila than do the older agents, such as erythromycin [20]. Against 85 isolates of L. pneumophila serogroup 1, the MIC90 values were $0.06 \mathrm{mg} \cdot \mathrm{L}^{-1}$ for clarithromycin, $0.5 \mathrm{mg} \cdot \mathrm{L}^{-1}$ for azithromycin and $1 \mathrm{mg} \cdot \mathrm{L}^{-1}$ for erythromycin [17].

The fluoroquinolones also exhibit good in vitro activity against atypical respiratory pathogens [15-20, 22, 26]. This class includes traditional agents, such as ciprofloxacin and ofloxacin, along with the newer respiratory fluoroquinolones (levofloxacin, gatifloxacin and moxifloxacin) and several investigational agents, such as gemifloxacin and garenoxacin. Against C. pneumoniae, the newer fluoroquinolones appear more potent than earlier derivatives, with MIC90 values for ciprofloxacin typically $\sim 1 \mathrm{mg} \cdot \mathrm{L}^{-1}$ as compared with: $0.25-0.5 \mathrm{mg} \cdot \mathrm{L}^{-1}$ for levofloxacin; $0.06 \mathrm{mg} \cdot \mathrm{L}^{-1}$ for moxifloxacin and gemifloxacin; and $0.007 \mathrm{mg} \cdot \mathrm{L}^{-1}$ for garenoxacin 
[16, 22, 24-26]. Newer fluoroquinolones, such as levofloxacin, are active in vitro against clinical isolates of $M$. pneumoniae, with MIC90 values of $0.125-0.25 \mathrm{mg} \cdot \mathrm{L}^{-1}$ similar to tetracyclines, but inferior to macrolides [15, 19]. They are, however, highly potent agents against $L$. pneumophila. Against 85 isolates of L. pneumophila serogroup 1, MIC90 values ranged from $0.016 \mathrm{mg} \cdot \mathrm{L}^{-1}$ for levofloxacin, moxifloxacin, grepafloxacin and gemifloxacin, to $0.03 \mathrm{mg} \cdot \mathrm{L}^{-1}$ for ciprofloxacin and ofloxacin [17].

Tetracyclines may also be used to treat infections caused by $C$. pneumoniae and $M$. pneumoniae. However, their in vitro potency is often inferior to that of the macrolides and fluoroquinolones $[15,16,19,23]$. Furthermore, there is evidence to suggest that strains of $M$. pneumoniae are developing resistance to tetracycline [23].

Chemically related to the macrolides, the ketolides are the most recent class of antibiotics to be developed for the treatment of RTIs and include the investigational agents telithromycin and ABT-773. They share the potent in vitro activity of the macrolides against atypical respiratory pathogens [20, 21, 25]. Against strains of $C$. pneumoniae, the MIC90 values of telithromycin and ABT-773 are typically $0.06 \mathrm{mg} \cdot \mathrm{L}^{-1}$ (range: $0.015-0.25 \mathrm{mg} \cdot \mathrm{L}^{-1}$ ) and $0.015 \mathrm{mg} \cdot \mathrm{L}^{-1}$ (range: $0.008-0.15 \mathrm{mg} \cdot \mathrm{L}^{-1}$ ), respectively $[21,25]$. ABT-773 shows similar in vitro activity to azithromycin against $L$. pneumophila, exhibiting MIC90 values of 0.015 and $0.03 \mathrm{mg} \cdot \mathrm{L}^{-1}$, respectively [20].

\section{Community-acquired pneumonia}

Prevalence. The failure to identify the causative pathogens, in as many as $50 \%$ of patients with symptoms of CAP, has made it difficult to determine its true microbial aetiology and, in particular, the causative role of atypical pathogens, since the observed prevalence rates are dependent on the diagnostic tests used [27]. Furthermore, some patients with CAP have mixed infections involving typical respiratory pathogens, e.g. as Streptococcus pneumoniae, Haemophilius influenzae and Moraxella catarrhalis, as well as atypical pathogens, which cannot be diagnosed initially with readily available clinical specimens.

While $S$. pneumoniae is still considered the major cause of CAP, surveys suggest that atypical respiratory pathogens are an increasingly frequent cause of illness, accounting for anything from $6-20 \%$ of ambulatory cases to $\geqslant 40 \%$ among patients hospitalised for CAP (table 1) [1, 27, 28,]. Other authors have estimated the contribution of atypical pathogens as $25 \%$ in Europe [42] and $22 \%$ in the USA [43].

Children are among those at high risk of contracting CAP due to infection with $C$. pneumoniae or $M$. pneumoniae [44], and studies suggest that incidence is age-related [45, 46]. In one study, the incidence of $C$. pneumoniae was two-fold higher in children $\geqslant 5$ yrs old than in those $<5$ yrs old [45]. In a separate study, in which the aetiology of CAP was determined in paediatric outpatients using a complete panel of diagnostic tests, $C$. pneumoniae was identified in $6 \%$ of patients aged between 6 months and 12 yrs, ranking behind $S$. pneumoniae (27\%), viruses $(20 \%)$ and M. pneumoniae (7\%) [47].

Elderly patients and those with comorbid cardiopulmonary diseases are also at increased risk of CAP due to $C$. pneumoniae, in whom the infection may develop into severe pneumonia [48, 49]. A survey, conducted among 101 elderly patients hospitalised for CAP, showed that infection with $C$. pneumoniae was second only to $S$. pneumoniae in frequency, when identified in $21 \%$ of patients with an aetiological diagnosis [50].

Legionellae have consistently been identified as a common cause of severe CAP, but their role in mild-to-moderate illness remains controversial [51]. Certainly, Legionella spp. are isolated with increasing frequency in patients with severe symptoms of pneumonia, and in many studies are the second highest cause of severe CAP after $S$. pneumoniae [51]. In a recent review of 41 prospective studies which sought to identify the microbial aetiology of CAP, L. pneumophila was identified as the causative pathogen in $1.9 \%$ of outpatients, $4.9 \%$ of hospitalised patients and $7.9 \%$ of intensive care unit patients [52]. Other independent studies have also reported a high prevalence of $L$. pneumophila infection among CAP patients admitted to hospital $[31,32]$. In one study, $20 \%$ of patients hospitalised for CAP had legionellosis [32].

Recent surveys indicate that $L$. pneumophila remains the

Table 1. - Prevalence of atypical respiratory pathogens (Chlamydia pneumoniae, Mycoplasma pneumoniae and Legionella spp.) in patients with community-acquired pneumonia (CAP)

\begin{tabular}{|c|c|c|c|c|c|c|}
\hline Patient status & Country & First author [ref no.] & Diagnostic method & $\begin{array}{c}C . \\
\text { pneumoniae }\end{array}$ & $\begin{array}{c}M . \\
\text { pneumoniae }\end{array}$ & $\begin{array}{l}\text { Legionella } \\
\text { spp. }\end{array}$ \\
\hline $\begin{array}{l}\text { Ambulatory and } \\
\text { hospitalised adults }\end{array}$ & Spain & ALMIRALL [28] & MIF/IFA & $16 / 105(15)$ & $8 / 105(8)$ & Not listed \\
\hline Ambulatory adults & Canada & MARRIE [29] & Complement fixation/IFA & $21 / 149(14)^{\#}$ & $39 / 149(26)^{\#}$ & $1 / 149(1)$ \\
\hline $\begin{array}{l}\text { Ambulatory and } \\
\text { hospitalised adults }\end{array}$ & USA & FILE [30] & Culture/direct FA test/MIF/EIA & $101 / 456(22)$ & $41 / 456(9)$ & $8 / 456(2)$ \\
\hline Hospitalised adults & Spain & SOPENA [31] & Culture/MIF/ & 41/392 (10) & $5 / 392(1)$ & $48 / 392(12)$ \\
\hline Hospitalised adults & France & AUBERTIN [32] & IFA & Not listed & $24 / 274(8)$ & $55 / 274(20)$ \\
\hline Hospitalised adults & Germany & STEINHOFF [33] & Culture/IFA/complement fixation & 27/236 (11) & $22 / 236(9)$ & Not listed \\
\hline Hospitalised adults & Israel & LEIBERMAN [34] & Serology & $62 / 346(18)$ & $101 / 346(29)$ & $56 / 346(16)$ \\
\hline Hospitalised adults & New Zealand & NEILL [35] & Culture & $8 / 255(3)$ & $41 / 255(16)$ & $27 / 255(11)$ \\
\hline \multirow[t]{2}{*}{ Hospitalised adults } & Netherlands & BOHTE [36] & IFA & $9 / 334(3)$ & $19 / 334(6)$ & $8 / 334(2)$ \\
\hline & Israel & BOLDUR [37] & IFA & NA & NA & $5-9$ \\
\hline ildren & India & CHAUDHRY [38] & IFA/EIA & $4 / 62(6)$ & $17 / 62(27)$ & NA \\
\hline Ambulatory adults & Switzerland & BOCHUD [39] & Complement fixation/IFA & $9 / 170(5)$ & 23/170 (14) & $1 / 170(1)$ \\
\hline Hospitalised elderly & USA & EL SOLH [40] & MIF/IFA & $1 / 104(1)$ & & $5 / 104(5)$ \\
\hline Not specified & Spain & $\begin{array}{l}\text { RUIZ-GONZALEZ } \\
\text { [41] }\end{array}$ & $\begin{array}{l}\text { Culture/serology/molecular } \\
\text { antigen tests }\end{array}$ & $9 / 109(8)$ & 19/109 (17) & Not listed \\
\hline
\end{tabular}

Data are presented as $\mathrm{n} /$ total $\mathrm{n}(\%)$ or $\%$, unless otherwise stated. Only a small selection of the vast array of published articles on CAP is represented in order to provide examples of the range of prevalence of CAP due to atypical pathogens on a multinational scale, and also in relation to diagnostic methods applied. MIF: microimmunofluorescence; IFA: indirect fluorescent antibody; EIA: enzyme immunoassay; NA: not available. ${ }^{\#}$ : includes five cases of mixed infection with M. pneumoniae and C. pneumoniae. 
primary cause of legionellosis, responsible for over $80 \%$ of cases, of which the majority are due to serogroup-1 pathogens [53]. The considerable variation in prevalence of $L$ pneumophila, observed at different times in the same location, suggests that infection due to this organism may be a seasonal and epidemic phenomenon [54-57]. Among other species recently isolated from patients with CAP, L. longbeachae occurred with a frequency of $3.9 \%, L$. bozemanii with a frequency of $2.4 \%$, and $L$. micdadei, L. dumoffii, L. feeleii, $L$. wadsworthii and $L$. anisa with a combined frequency of $2.2 \%$ [53]. Interestingly, L. longbeachae constituted 30.4\% of clinical isolates in Australia and New Zealand [53].

Legionella spp. are emerging as one of the most common causes of severe CAP, with current figures probably an underestimate of the true prevalence of legionellosis, given that many species and serogroups cannot be identified accurately by contemporary commercial microbiological tests [51].

An Asian epidemiological study determined the frequency of infection with $M$. pneumoniae, $C$. pneumoniae and Legionella spp., in patients presenting with symptoms of CAP at 12 medical centres in Asian countries, using standardised laboratory techniques and interpretation criteria (NGEOW et al., Institute for Medical Research,Bacteriology Division, Jalan Pahang, Kuala Lumpur, Malaysia, unpublished data). Aetiological diagnosis was based on seroconversion or significant changes in antibody titre together with the presence of bacterial DNA in respiratory secretions, in the case of $M$. pneumoniae and $C$. pneumoniae infections, or bacterial antigen in urine, in the case of $L$. pneumophila serogroup 1. Results for paired (acute and convalescent) sera from 1,374 patients showed that $23.5 \%$ of cases were caused by infection with atypical pathogens, with $M$. pneumoniae, C. pneumoniae, and $L$. pneumophila accounting for $12.2 \%, 4.7 \%$ and $6.6 \%$ of cases respectively. Persisting high antibody titres, indicative of past exposure to $M$. pneumoniae, $C$. pneumoniae and $L$. pneumophila, were seen in $10.2 \%, 4.8 \%$ and $18.9 \%$ of patients respectively, reflecting the overall high prevalence $(33.9 \%)$ of these pathogens in the aetiology of CAP in Asia.

Clinical course of atypical infection. The term "primary atypical pneumonia", which was used to describe pneumonia due to infection with $M$. pneumoniae in the late 1930s and early 1940s, is no longer considered appropriate as a diagnosis in patients infected with atypical respiratory pathogens. Indeed, it is now widely recognised that the clinical course of CAP is similar whether caused by typical or atypical respiratory pathogens [29]. Therefore, it is unwise to select antibiotic therapy solely on the basis of clinical manifestations, such as fever, chills, productive cough and pleuritic chest pain, or radiological evidence of CAP [58], even when legionellosis is suspected.

Therapy. Given the prevalence of atypical pathogens in the aetiology of CAP and the likelihood that current figures underestimate their true prevalence, empirical antibiotic therapy for CAP should ideally provide coverage against atypical pathogens. Treatment should be based on the premise that all patients with CAP could be potentially infected with $C$. pneumoniae, M. pneumoniae or Legionella spp., either alone or as part of a mixed infection [27]; an approach that is, in fact, advocated in several new treatment guidelines for CAP.

C. pneumoniae is commonly found in infections of mixed aetiology and may predispose to co-infection with other microorganisms, e.g. S. pneumoniae [59]. In patients co-infected with $C$. pneumoniae and $S$. pneumoniae, the clinical picture is often more severe than that seen with monomicrobial infection and, as one study showed, can result in prolonged hospitalisation if antibiotic therapy is directed solely to the eradication of $S$. pneumoniae [60].

The need to provide coverage against atypical pathogens in empirical prescribing for CAP is now recognised in national guidelines, in which macrolides with proven activity against atypical pathogens are widely advocated [14, 27, 61-64]. Studies have shown that the inclusion of a macrolide in treatment regimens can improve clinical outcome in children with lower RTIs due to atypical pathogens [65], including those with CAP [66], in whom it is especially difficult to determine the microbial aetiology.

For empirical therapy, the IDSA [14], Center for Disease Control and Prevention [63], Canadian Infectious Disease Society and Canadian Thoracic Society (CIDS/CTS) [64], and the American Thoracic Society (ATS) [27] all recommend macrolides for first-line use in outpatients without modifying factors. The British Thoracic Society [61] and South African Thoracic Society (SATS) [62] guidelines, respectively, support the use of macrolides as an alternative monotherapy in outpatients or as monotherapy when atypical infection is suspected. In outpatients with modifying factors, such as the elderly or those with comorbidity, the ATS [27] and CIDS/ CTS [64] suggest macrolides are used in conjunction with other antibiotics. The inclusion of macrolides in combination regimens is also widely advocated for patients hospitalised with CAP. SATS guidelines [62] recommend the use of macrolides as an adjunct to $\beta$-lactams or fluoroquinolones, if atypical infection is suspected.

A number of studies have shown that adherence to guidelines for empirical prescribing in CAP results in significant improvement in clinical outcome [67-71]. Treatment consistent with the ATS guidelines [27], for example, in which macrolides are recommended for atypical coverage, has been shown to significantly reduce length of hospitalisation as well as mortality from CAP [67, 69, 70].

Recently published data have confirmed the prevalence of atypical pathogens in paediatric CAP patients [66], highlighting their significant role in the pathogenesis of the disease and the need to reassess antibiotic therapy with $\beta$-lactam agents. In 196 children with CAP aged 2-5 yrs, S. pneumoniae infections were diagnosed in $24.5 \%$ of patients, atypical bacterial infections in $23.5 \%$ of patients, and mixed $S$. pneumoniae and atypical bacterial infections in $8.2 \%$ of children. Clinical, laboratory and radiological features were of limited use in predicting the aetiology of CAP. Clinical failures occurred significantly more frequently 4-6 weeks post-treatment, among children with atypical bacterial or mixed infection who were not originally treated with a macrolide (fig. 2).

\section{COPD}

\section{Prevalence of COPD}

Chronic obstructive pulmonary disease (COPD) is a chronic, smoking-related inflammatory disorder of the lungs, in which persistent infection with $C$. pneumoniae is believed to play a significant role in the underlying pathology [2, 72-74]. A hypothetical model has been proposed to describe how chronic $C$. pneumoniae infection in respiratory-tract tissue may amplify smoking associated inflammation in the bronchi and, hence, contribute to the development of irreversible pathological changes characterised by airway obstruction [74]. Certainly, there is evidence to show that chronic colonisation with $C$. pneumoniae, as assessed by PCR, is significantly associated with impaired lung function [75], and that infection appears much more common in COPD patients than in 


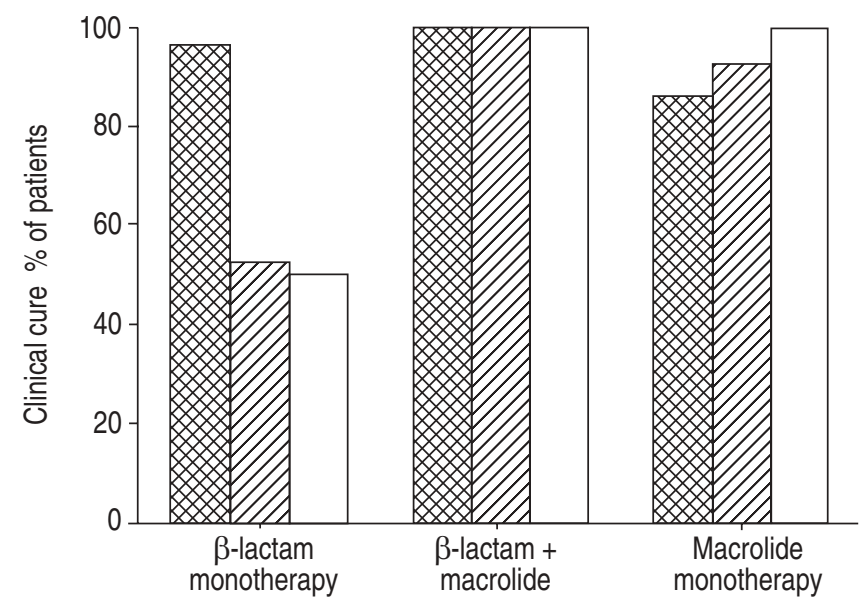

Fig. 2.-Comparison of clinical outcome by type of antibiotic therapy adapted from [56]. $\beta$-lactam monotherapy: $n=53$; $\beta$-lactam monotherapy+macrolide: $\mathrm{n}=22$; macrolide monotherapy: $\mathrm{n}=26$. $\mathbf{*}$ : Streptococcus pneumoniae $(\mathrm{n}=44)$; $\mathbb{Z}$ : atypical bacteria $(\mathrm{n}=42) ; \square$ : mixed $S$. pneumoniae +atypical bacteria $(\mathrm{n}=44)$.

age-matched controls $[72,75,76]$. Chronic infection may also predispose to airway colonisation with other pathogens, and so fuel the vicious cycle of chronic airway inflammation [77].

\section{Prevalence of acute exacerbations of chronic bronchitis}

Patients with COPD, the majority of whom have chronic bronchitis, are prone to acute exacerbation in which bacteria are estimated to be responsible for approximately half of all cases [78]. H. influenzae, M. catarrhalis, S. pneumoniae and C. pneumoniae are the most important causes of acute exacerbation of bacterial origin [78]; although, the incidence of $C$. pneumoniae in patients with acute exacerbations of chronic bronchitis (AECB) appears to vary considerably from as low as $4-5 \%$ to $>30 \%$ (table 2 ) $[72,75,79-84]$.

\section{Therapy}

The value of antibiotic therapy in the management of AECB was established in a landmark placebo-controlled trial in 1987, in which 173 patients with AECB, graded according to the presence of the three cardinal symptoms of increased dyspnoea, increased sputum and increased purulence, were treated with trimethoprim-sulphamethoxazole, amoxicillin or doxycycline. Results showed that antibiotic therapy achieved significantly greater rates of clinical success than placebo and that it was most effective in the more severely ill patients [78].
A subsequent meta-analysis of nine randomised placebo controlled trials of antibiotic therapy in patients with AECB has confirmed these findings [86].

The early antibiotic trials in AECB generally involved treatment with standard antibiotics, such as oxytetracycline, ampicillin, chloramphenicol, tetracycline, amoxicillin and trimethoprim-sulphamethoxazole, which more recent analyses suggest are less effective than many newer agents that are often reserved for second- or third-line use. In a retrospective analysis of antibiotic therapy for AECB, treatment with amoxicillin/clavulanate, second-generation macrolides, such as azithromycin, and fluoroquinolones significantly reduced the rate of clinical failure, the need for hospitalisation and overall costs, as well as extending the interval between exacerbations compared with older agents [87]. Against this evidence, one study showed that of the $80-100 \%$ of patients who received antibiotics for AECB, 13-25\% experienced clinical failure [88].

Evidence based guidelines, analogous to those for CAP, have yet to be fully developed for AECB, although there have been attempts to classify treatment by baseline severity of disease and severity of exacerbation $[89,90]$. Where they exist, the guidelines focus primarily on antibiotic coverage of $H$. influenzae, M. catarrhalis and S. pneumoniae, but also include agents effective against atypical respiratory pathogens. The guidelines from the European Respiratory Society, for example, recognise that atypical pathogens, such as $M$. pneumoniae and $C$. pneumoniae, may be implicated in COPD exacerbations and that macrolides, fluoroquinolones and tetracyclines are effective in such cases. These aetiologies, in addition to noninfectious causes, should therefore be taken into consideration when patients with $\mathrm{AECB}$ fail to respond to initial therapy [90].

\section{Asthma}

\section{Aetiology}

Asthma, a chronic inflammatory disease of the airways, is characterised by bronchial constriction together with symptoms of cough, wheezing and difficulty breathing. Its aetiology is complex, involving interactions between genetic susceptibility, exposure to allergens and external aggravating factors, such as smoking, air pollution and RTIs [91]. A link between asthma and RTIs was first established in the early 1970 s, although at the time it was unclear whether respiratory pathogens were involved in either the initiation or promotion of asthma [92]. Acute RTIs are now known to worsen asthma, particularly in children, in whom they account for between $14-45 \%$ of acute exacerbations [93]. Although the incidence of RTIs in adult asthma patients was always believed to be lower, a recent study found that $37 \%$ of adults admitted to

Table 2. - Incidence of Chlamydia pneumoniae in patients with acute exacerbations of chronic bronchitis

\begin{tabular}{llllr}
\hline Location & First author [ref no.] & Year & Diagnostic method & C. pneumoniae \\
\hline Italy & BLASI [72] & $1990-1991$ & IFA & $5 / 142(4)$ \\
Italy & BLASI [75] & $2002^{\#}$ & PCR and MIF & $2 / 34(6)$ \\
USA & BEATY [79] & $1987-1988$ & MIF & $2 / 44(5)$ \\
Japan & MIYASHITA [80] & $1993-1996$ & MIF & $6 / 77(7.8)$ \\
Spain & SOLER [81] & $1998^{\#}$ & Serology (tests not specified) & $7 / 38(18)$ \\
Turkey & MOGULKOC [82] & $1999^{\#}$ & MIF & $11 / 49(22)$ \\
Turkey & KARNAK [83] & $2001^{\#}$ & MIF & $13 / 38(34)$ \\
UK & SEEMUNGAL [84] & $2002^{\#}$ & PCR & $9 / 33(28)$ \\
\hline
\end{tabular}

Data are presented as n/total n (\%), unless otherwise stated. IFA: indirect fluorescent antibody; PCR: polymerase chain reaction; MIF: microimmunofluorescence. ${ }^{\#}$ : date of publication, period during which specimens were collected and analysed was not specified. 
hospital over a 12-month period with an acute asthma exacerbation had evidence of recent RTI [93]. These findings suggest that RTIs may precipitate a worsening of asthma in adults as well as children.

\section{Role of atypical pathogens}

Of nonviral pathogens implicated in asthma, infection with $M$. pneumoniae and $C$. pneumoniae has been linked to a worsening of asthma. Evidence from in vitro animal studies indicates that atypical respiratory pathogens may play a role in the pathogenesis of the disease [92]. Mice infected with $M$. pneumoniae, for example, can develop a chronic pulmonary infection characterised by airway hypersensitivity, airway obstruction and histological inflammation, which lends support to the notion that $M$. pneumoniae infection may cause chronic pulmonary disease with functional airway obstruction, as seen in asthma patients [94].

There is some clinical evidence to suggest that acute infection with $C$. pneumoniae and $M$. pneumoniae might initiate asthma in some previously asymptomatic patients, although the quantitative role of these atypical pathogens in this role is unknown $[91,95,96]$. Furthermore, infection with $C$. pneumoniae may interact with allergic inflammation to increase asthma symptoms [97-99]. A causal link has been established between repeated or prolonged exposure to $C$. pneumoniae and wheezing, asthmatic bronchitis and asthma [100], as well as to acute episodes of wheezing in children with asthma [101]. C. pneumoniae has also been associated with persistent cough [102-104].

\section{Exacerbations}

Evidence currently available supports a role for C. pneumoniae and $M$. pneumoniae infection as a trigger for 5-30\% episodes of wheezing or acute asthma exacerbations [91, 105]. In one study of adults with asthma, infection with $C$. pneumoniae was responsible for $10 \%$ of all acute exacerbations [106], similar to rates reported in children aged 5-16 yrs experiencing an acute episode of wheezing [101]. The higher prevalence rates of $C$. pneumoniae among adults with asthma, as compared to age-matched controls, have also been linked to acute exacerbations [107].

Asthmatic children hospitalised for severe asthma attacks tend to have a high incidence of RTIs. In one study, infection with $C$. pneumoniae and $M$. pneumoniae occurred with a frequency of $4.5 \%$ and $2.2 \%$ respectively, in children hospitalised with severe asthma [108]. However, a recent study in adults with asthma showed that of $C$. pneumoniae, Coxiella burnetti, M. pneumoniae and L. pneumophila, only acute infection with $M$. pneumoniae was associated with the need for hospitalisation for acute exacerbation for bronchial asthma. Furthermore, most patients infected with $M$. pneumoniae had concomitant respiratory viral infections, making it difficult to determine the precise role of $M$. pneumoniae in eliciting a severe asthma attack [109].

\section{Chronic asthma}

Evidence that $C$. pneumoniae can induce acute exacerbations and trigger wheezing in patients with asthma has led to suggestions that chronic $C$. pneumoniae infection may be involved in the natural history of asthma conditioning, by contributing to the chronic inflammation and the airways hyper-responsiveness that is the hallmark of the disease [5].
However, whether chronic infection or colonisation with $C$. pneumoniae or $M$. pneumoniae plays a role in persistent asthma symptoms or severity remains unclear [91, 95].

The possible role of $C$. pneumoniae chronic infection in determining asthma severity in adults has been hypothesised by BLACK et al. [110]. The authors described 619 asthmatic subjects screened in a large multinational study of the effect of antibiotic treatment in asthmatic subjects seropositive for C. pneumoniae. In the screened population, $\operatorname{IgG}$ and $\operatorname{IgA}$ antibodies to $C$. pneumoniae were associated with asthma severity markers. A positive association was found between antibodies to $C$. pneumoniae and the use of high-dose inhaled steroids, higher daytime symptom scores and an inverse association with forced expiratory volume in one second (FEV1) as a percentage of the predicted value. These findings once again raise the possibility that chronic $C$. pneumoniae infection may lead to an increase in asthma severity.

Both $C$. pneumoniae and $M$. pneumoniae are present either alone or together in the airways of significant numbers of patients with chronic, stable asthma [111]. Interestingly, patients infected with these pathogens also have significantly more tissue mast cells than uninfected patients. There is also evidence to suggest that frequent bacterial infections in infancy may protect against later atopy, which could account for the low rates of atopic asthma in some indigenous populations around the world [105].

\section{Therapy}

Although antibiotic therapy is not routinely advocated in the management of acute asthma, there is evidence to suggest that in adult patients with uncontrolled steroid-dependent asthma and recent infection with $C$. pneumoniae, treatment with macrolides (clarithromycin or azithromycin) can greatly improve symptoms and reduce dependence on steroids [112]. In addition to their antimicrobial activity against atypical pathogens, macrolides may also improve symptoms and pulmonary function in patients with asthma by virtue of their anti-inflammatory activities [113].

Two studies have investigated the suppressive effects of macrolides on bronchial hyperresponsiveness in adult patients with asthma. In an 8-week, randomised, placebo-controlled trial, AMAYASU et al. [114] showed that treatment with clarithromycin (200 mg b.i.d.) had bronchial anti-inflammatory effects, which were associated with a significant decrease in eosinophil counts, and hence interleukin-8 release, compared with placebo in patients with mild or moderate stable asthma. Values for allergen provocative concentration causing a 20\% drop in FEV1 (PC20) were also improved. Similarly, EKICI et al. [115] found that administration of low-dose, intermittent azithromycin $(250 \mathrm{mg} \mathrm{b.i.w.)}$ to patients with mild asthma resulted in significantly increased values for PC20, although FEV1 values did not differ significantly after 8 weeks of treatment.

BLACK et al. [116] studied the effect of roxithromycin in subjects with asthma and $\mathrm{IgG}$ antibodies to $C$. pneumoniae $\geqslant 1: 64$ and/or IgA antibodies $\geqslant 1: 16$. In their study, 6 weeks of treatment with roxithromycin $150 \mathrm{mg}$ b.i.d., compared with placebo, led to significant improvement in evening peak expiratory flow at the end of treatment, but the difference between the groups diminished thereafter (fig. 3). Although there was a trend for improvements in the symptom score, this was not significant.

In his comment of this paper, JoHNSTON [117] has highlighted that, although $C$. pneumoniae infection resulted in the clinical benefit observed at the end of treatment, reinfection after cessation of treatment resulted in the loss of 


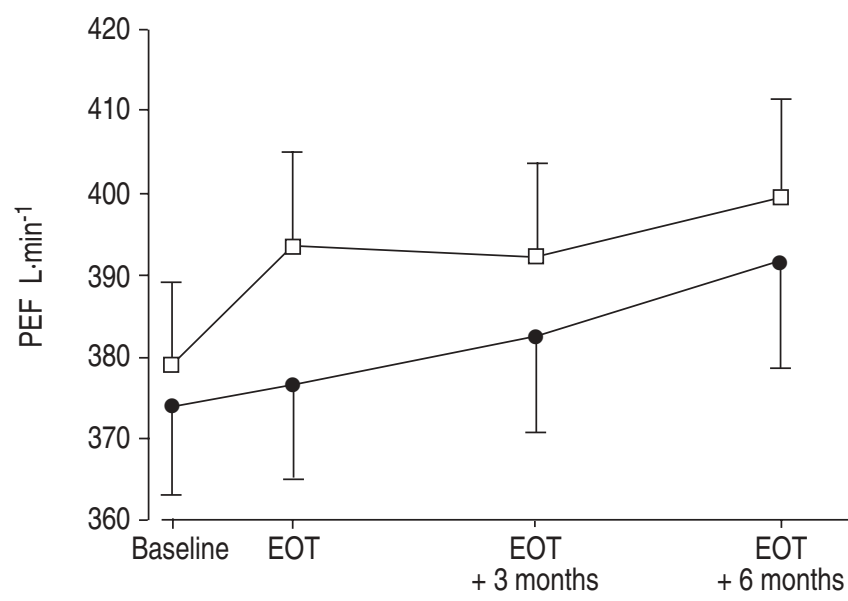

Fig. 3.-Improvement in evening peak expiratory flow (PEF) for subjects with asthma upon treatment with roxithromycin $(\square)$ or placebo $(-)$. EOT: end of therapy. Reproduced with kind permission from BLACK et al. [116].

benefit during follow-up. In another study, the administration of clarithromycin $(500 \mathrm{mg}$ b.i.d.) to patients with chronic stable asthma in a 6-week randomised, placebo-controlled trial showed that antibiotic therapy was significantly more effective than placebo in improving lung function where patients were PCR-positive for $M$. pneumoniae or $C$. pneumoniae [118]. These and other studies should help to determine whether antibiotic therapy can contribute to an improvement in asthma control in individual patients, as well as alter the natural course of the disease [92].

\section{Upper respiratory tract infections}

Acute sinusitis. In contrast to infections of the lower respiratory tract, upper RTIs, such as acute bacterial sinusitis, rarely involve infection with atypical respiratory pathogens $[2,119$, 120]. Even among HIV patients with AIDS, in whom the incidence of acute sinusitis is high, there is little evidence to suggest that atypical bacterial pathogens are involved in infections [120, 121].

Acute sinusitis, characterised by sinus pain and nasal congestion/discharge, usually develops secondary to an upper RTI, such as a cold, and is especially common in children [122]. While some studies show antibiotic therapy is effective in relieving symptoms of persistent purulent nasal discharge and cough, others show no significant clinical benefit over placebo [122, 123].

In patients with persistent symptoms, and in whom an aetiological diagnosis cannot be established, treatment options include amoxicillin, high-dose amoxicillin, trimethoprim-sulphamethoxazole or amoxicillin/clavulanate if there is a high risk of resistant pathogens [122, 123]. Several clinical studies have shown that newer antibiotics are as effective as older standard agents in treating acute sinusitis in adults and children [124-126]; although, for patients with acute uncomplicated sinusitis, the cost of care is significantly higher with newer, second-line agents [127].

Paediatric acute otitis media. Acute otitis media is one of the most common childhood infections, the incidence of which has increased steadily during the past $15 \mathrm{yrs}$, largely due to increased use of child daycare centres [128]. Recent surveys indicate that the typical respiratory pathogens $S$. pneumoniae, $H$. influenzae and M. catarrhalis remain the predominant cause of acute otitis media, but their respective prevalence and age distribution show marked age and geographical variation [129, 130]. Among younger children, $C$. pneumoniae has been identified as a cause of acute otitis media. In one study, $C$. pneumoniae was recovered following tympanocentesis from $8 \%$ of children with acute otitis media [129].

The value of antibiotic therapy in the treatment of acute otitis media is controversial, some physicians advocate withholding antibiotics until absolutely necessary. However, complications and adverse clinical sequelae of otitis media, such as perforation of the tympanic membrane, facial paralysis, otorrhoea and mastoiditis, are still prevalent and, although rare, can be life-threatening [131]. Physicians are frequently under great pressure from parents to prescribe antibiotics for upper RTIs whether appropriate or not. A recent survey found that $48 \%$ of the physicians interviewed had been pressurised by parents to prescribe antibiotics for their children, and that a third had complied in the face of such pressure, even when such therapy was not indicated [132].

The Netherlands, in contrast to most industrialised countries, is among the few not to routinely treat acute otitis media with antibiotics. Instead, physicians prefer to provide only symptomatic treatment initially, and to wait for improvement for $24 \mathrm{~h}$ in patients under 2 yrs, or 3 days in those over 2 yrs, before prescribing antibiotics [133]. Elsewhere, antibiotic therapy is usually prescribed coincident with a clinical diagnosis of acute otitis media [132]. Meta-analyses of randomised controlled trials of antibiotic therapy in acute otitis media show that, compared with placebo, such therapy speeds the resolution of symptoms [134]. Short-course therapy over 3-5 days with azithromycin, which covers atypical respiratory pathogens, indicates equal effectiveness as longer courses of standard $\beta$-lactams in acute uncomplicated otitis media [124].

Tonsillopharyngitis. Pharyngitis is another common upper RTI, especially among children. It ranges from a mild selflimiting illness characterised by sore throat, to one with severe and potentially life-threatening complications such as acute rheumatic fever and glomerulonephritis. Infection with Group A $\beta$-haemolytic streptococcus (GAS) is the most common bacterial cause of pharyngitis. Other bacterial aetiologies include other haemolytic streptococci, staphylococci, pneumococci, H. influenzae, Arcanobacterium haemolyticum, Mycoplasma spp., Chlamydia spp. and anaerobes [125]. M. pneumoniae and $C$. pneumoniae are generally considered infrequent causes of acute pharyngitis [135].

Antibiotic therapy focuses primarily on the eradication of GAS from the upper respiratory tract, for which the IDSA recommends penicillin for first-line use [135], an approach consistent with other guidelines [136, 137]. Other effective treatments include macrolides, aminopenicillins, first- and second-generation cephalosporins and clindamycin [135]. In patients allergic to penicillin, erythromycin is advocated as a suitable alternative [135] or newer macrolides, such as azithromycin, which have similar activity to erythromycin against GAS, but are better tolerated, should be prescribed $[136,137]$. There is no evidence to suggest that atypical pathogens should be covered by antibiotic treatment.

\section{Conclusions}

As this review illustrates, the atypical respiratory pathogens, $C$. pneumoniae, M. pneumoniae and Legionella spp., have an important and broad role in acute infections of the lower and, to a lesser extent, upper respiratory tract. The true 
prevalence of these pathogens in acute RTIs remains unclear, as it relies on the sensitivity and specificity of currently available diagnostic methods. Nonetheless, they are clearly significant contributors in acute RTIs, either as primary pathogens or co-pathogens. C. pneumoniae is also implicated in a number of chronic infectious conditions, both as a trigger and as an exacerbating factor. There is a clear requirement for standardisation in detection methods for atypical pathogens. Wider use of PCR to accurately determine the presence of atypical pathogens in respiratory secretions requires further development work to produce a rapid, reproducible and costeffective test.

Given the increasingly important role of atypical pathogens in respiratory-tract infections, the balance of opinion at present supports the use of antibiotics that includes activity against these pathogens whenever they are suspected. In vitro studies demonstrate that macrolides, tetracyclines, fluoroquinolones and ketolides possess activity against atypical pathogens, and these findings are supported by clinical studies that have included patients with infections due to Chlamydia pneumoniae, Mycoplasma pneumoniae or Legionella spp. Macrolides have proven efficacy against atypical respiratory pathogens and are advocated for first-line use in most guidelines for treatment of community-acquired pneumonia, where they are indicated either alone or in combination with other antibiotics. The fluoroquinolones are also active against these pathogens. Recognition of the clinical importance of the atypical respiratory pathogens makes it important to monitor the emergence of antibiotic resistance strains, especially to commonly used antibiotics such as macrolides.

\section{References}

1. File TM Jr, Tan JS, Plouffe JF. The role of atypical pathogens: Mycoplasma pneumoniae, Chlamydia pneumoniae, and Legionella pneumophila in respiratory infection. Infect Dis Clin North Am 1998; 12: 569-592.

2. Blasi F, Cosentini R, Tarsia P. Chlamydia pneumoniae respiratory infections. Curr Opin Infect Dis 2000; 13: 161164.

3. Grayston JT, Kuo CC, Wang SP, Altman J. A new Chlamydia psittaci strain, TWAR, isolated in acute respiratory tract infections. $N$ Engl J Med 1986; 315: 161-168.

4. Grayston JT, Kuo CC, Campbell LA. Chlamydia pneumoniae sp. nov. for Chlamydia sp. strain TWAR. Int J Sys Bacteriol 1989; 39: 88-90.

5. Blasi F, Tarsia P, Arosio C, Fagetti L, Allegra L. Epidemiology of Chlamydia pneumoniae. Clin Microbiol Infect 1998; 4: Suppl. 4, S1-S6.

6. Marrie TJ. Chlamydia pneumoniae. Thorax 1993; 48: 1-4.

7. Thom DH, Grayston JT. Infections with Chlamydia pneumoniae strain TWAR. Clin Chest Med 1991; 12: 245-256.

8. Fields BS, Benson RF, Besser RE. Legionella and Legionnaires' disease: 25 years of investigation. Clin Microbiol Rev 2002; 15: 506-526.

9. Fraser DW, Tsai TR, Orenstein W, et al. Legionnaires' disease: description of an epidemic of pneumonia. N Engl J Med 1977; 297: 1189-1197.

10. Eaton MD, Meikeljohn G, van Herick W. Studies on the etiology of primary atypical pneumonia: a filterable agent transmissible to cotton rats, hamsters and chick embryos. J Exper Med 1944; 79: 649.

11. Chanock RM, Rifkind D, Dravetz HM. Respiratory disease in volunteers infected with Eaton agent: a preliminary report. Proc Natl Acad Sci USA 1961; 47: 887-890.

12. Taylor-Robinson D. The importance of mycoplasmas in respiratory infections. Dev Biol Stand 1975; 28: 86-100.
13. Murdoch DR. Nucleic acid amplification tests for the diagnosis of pneumonia. Clin Infect Dis 2003; 36: 11621170 .

14. Bartlett JG, Dowell SF, Mandell LA, File Jr TM, Musher DM, Fine MJ. Practice guidelines for the management of community-acquired pneumonia in adults. Infectious Diseases Society of America. Clin Infect Dis 2000; 31: 347-382.

15. Critchley IA, Jones ME, Heinze PD, et al. In vitro activity of levofloxacin against contemporary clinical isolates of Legionella pneumophila, Mycoplasma pneumoniae and Chlamydia pneumoniae from North America and Europe. Clin Microbiol Infect 2002; 8: 214-221.

16. Donati M, Pollini GM, Sparacino M, Fortugno MT, Laghi E, Cevenini R. Comparative in vitro activity of garenoxacin against Chlamydia spp. J Antimicrob Chemother 2002; 50: 407-410.

17. Dubois J, St-Pierre C. Comparative in vitro activity and postantibiotic effect of gemifloxacin against Legionella spp. $J$ Antimicrob Chemother 2000; 45: Suppl. 1, 41-46.

18. Edelstein PH, Shinzato T, Doyle E, Edelstein MA. In vitro activity of gemifloxacin (SB-265805, LB20304a) against Legionella pneumophila and its pharmacokinetics in guinea pigs with L. pneumophila pneumonia. Antimicrob Agents Chemother 2001; 45: 2204-2209.

19. Ikejima H, Yamamoto H, Ishida K, Kaku M, Shimada J. Evaluation of in vitro activity of new quinolones, macrolides, and minocycline against Mycoplasma pneumoniae. J Infect Chemother 2000; 6: 148-150.

20. Jung R, Danziger LH, Pendland SL. Intracellular activity of ABT-773 and other antimicrobial agents against Legionella pneumophila. J Antimicrob Chemother 2002; 49: 857-861.

21. Miyashita N, Fukano H, Niki Y, Matsushima T. In vitro activity of telithromycin, a new ketolide, against Chlamydia pneumoniae. J Antimicrob Chemother 2001; 48: 403-405.

22. Roblin PM, Hammerschlag MR. In vitro activity of a new antibiotic, NVP-PDF386 (VRC4887), against Chlamydia pneumoniae. Antimicrob Agents Chemother 2003; 47: 14471448.

23. Sato K. Evaluation of in vitro activity of new quinolones, macrolides, and minocycline against Mycoplasma pneumoniae. J Infect Chemother 2000; 6: 188.

24. Blasi F, Drago L, Gismondo MR, et al. In vitro antibiotic activity against Chlamydia pneumoniae clinical isolates. $J$ Chemother 2003; 15: 93-94.

25. Strigl S, Roblin PM, Reznik T, Hammerschlag MR. In vitro activity of ABT 773, a new ketolide antibiotic, against Chlamydia pneumoniae. Antimicrob Agents Chemother 2000; 44: 1112-1113.

26. Miyashita N, Fukano H, Yoshida K, Niki Y, Matsushima T. In vitro activity of moxifloxacin and other fluoroquinolones against Chlamydia species. J Infect Chemother 2002; 8: 115117.

27. Niederman MS, Mandell LA, Anzueto A, et al. Guidelines for the management of adults with community-acquired pneumonia. Diagnosis, assessment of severity, antimicrobial therapy, and prevention. Am J Respir Crit Care Med 2001; 163: $1730-1754$.

28. Almirall J, Morato I, Riera F, et al. Incidence of communityacquired pneumonia and Chlamydia pneumoniae infection: a prospective multicentre study. Eur Respir J 1993; 6: 14-18.

29. Marrie TJ, Peeling RW, Fine MJ, Singer DE, Coley CM, Kapoor WN. Ambulatory patients with communityacquired pneumonia: the frequency of atypical agents and clinical course. Am J Med 1996; 101: 508-515.

30. File TM Jr, Segreti J, Dunbar L, et al. A multicenter, randomized study comparing the efficacy and safety of intravenous and/or oral levofloxacin versus ceftriaxone and/ or cefuroxime axetil in treatment of adults with communityacquired pneumonia. Antimicrob Agents Chemother 1997; 41: $1965-1972$.

31. Sopena N, Sabria-Leal M, Pedro-Botet ML, et al. Comparative study of the clinical presentation of Legionella 
pneumonia and other community-acquired pneumonias Chest 1998; 113: 1195-1200.

32. Aubertin J, Dabis F, Fleurette J, et al. Prevalence of legionellosis among adults: a study of community-acquired pneumonia in France. Infection 1987; 15: 328-331.

33. Steinhoff D, Lode H, Ruckdeschel G, et al. Chlamydia pneumoniae as a cause of community-acquired pneumonia in hospitalized patients in Berlin. Clin Infect Dis 1996; 22: 958 964.

34. Lieberman D, Lieberman D, Porath A. Seasonal variation in community-acquired pneumonia. Eur Respir J 1996; 9: 26302634.

35. Neill AM, Martin IR, Weir R, et al. Community acquired pneumonia: aetiology and usefulness of severity criteria on admission. Thorax 1996; 51: 1010-1016.

36. Bohte R, van Furth R, van den Broek PJ. Aetiology of community-acquired pneumonia: a prospective study among adults requiring admission to hospital. Thorax 1995; 50: 543547.

37. Boldur I, Hoffmann S, Kazak R, Benjamin B. Legionellosis in Israel- a view of the situation. Harefuah 1999; 136: 257-61, 340 .

38. Chaudhry R, Nazima N, Dhawan B, Kabra SK. Prevalence of Mycoplasma pneumoniae and Chlamydia pneumoniae in children with community acquired pneumonia. Indian J Pediatr 1998; 65: 717-721.

39. Bochud PY, Moser F, Erard P, et al. Community-acquired pneumonia. A prospective outpatient study. Medicine (Baltimore) 2001; 80: 75-87.

40. El Solh AA, Sikka P, Ramadan F, Davies J. Etiology of severe pneumonia in the very elderly. Am J Respir Crit Care Med 2001; 163: 645-651.

41. Ruiz-Gonzalez A, Falguera M, Nogues A, Rubio-Caballero M. Is Streptococcus pneumoniae the leading cause of pneumonia of unknown etiology? A microbiologic study of lung aspirates in consecutive patients with communityacquired pneumonia. Am J Med 1999; 106: 385-390.

42. Woodhead M. Community-acquired pneumonia guidelinesan international comparison: a view from Europe. Chest 1998; 113: 183S-187S

43. Eron JJ. Etiology of community-acquired pneumonia. Hosp Formul 1994; 29: 122-136.

44. Block S, Hedrick J, Hammerschlag MR, Cassell GH, Craft JC. Mycoplasma pneumoniae and Chlamydia pneumoniae in pediatric community-acquired pneumonia: comparative efficacy and safety of clarithromycin versus erythromycin ethylsuccinate. Pediatr Infect Dis J 1995; 14: 471-477.

45. Heiskanen-Kosma T, Korppi M, Jokinen C, et al. Etiology of childhood pneumonia: serologic results of a prospective, population-based study. Pediatr Infect Dis J 1998; 17: 986991.

46. Principi N, Esposito S, Blasi F, Allegra L. Role of Mycoplasma pneumoniae and Chlamydia pneumoniae in children with community-acquired lower respiratory tract infections. Clin Infect Dis 2001; 32: 1281-1289.

47. Wubbel L, Muniz L, Ahmed A, et al. Etiology and treatment of community-acquired pneumonia in ambulatory children. Pediatr Infect Dis J 1999; 18: 98-104.

48. Cosentini R, Blasi F, Raccanelli R. Severe communityacquired pneumonia: a possible role for Chlamydia pneumoniae. Respiration 1996; 63: 61-65.

49. Pacheco A, Gonzales SJ, Aroncena C, Rebollar M, Anrela A, Guerrero A. Community-acquired pneumonia caused by Chlamydia pneumoniae strain TWAR in chronic cardiopulmonary disease in the elderly. Respiration 1991; 58: 316320.

50. Riquelme R, Torres A, El Ebiary M, et al. Communityacquired pneumonia in the elderly: a multivariate analysis of risk and prognostic factors. Am J Respir Crit Care Med 1996; 154: $1450-1455$.

51. Roig J, Rello J. Legionnaires' disease: a rational approach to therapy. J Antimicrob Chemother 2003; 51: 1119-1129.
52. Woodhead M. Community-acquired pneumonia in Europe: causative pathogens and resistance patterns. Eur Respir $J$ 2002; 36: Suppl., 20s-27s.

53. Yu VL, Plouffe JF, Pastoris MC, et al. Distribution of Legionella species and serogroups isolated by culture in patients with sporadic community-acquired legionellosis: an international collaborative survey. J Infect Dis 2002; 186: $127-128$.

54. Bercovier H, Fattal B, Shuval H. Seasonal distribution of legionellae isolated from various types of water in Israel. Isr J Med Sci 1986; 22: 644-646.

55. Fliermans CB, Cherry WB, Orrison LH, Smith SJ, Tison DL, Pope DH. Ecological distribution of Legionella pneumophila. Appl Environ Microbiol 1981; 41: 9-16.

56. Garcia-Fulgueiras A, Navarro C, Fenoll D, et al. Legionnaires' disease outbreak in Murcia, Spain. Emerg Infect Dis 2003; 9: 915-921.

57. Wang N. Study on seasonality of 1-8 serotypes legionella pneumophila infections. Zhonghua Liu Xing Bing Xue Za Zhi 1990; 11: 68-71.

58. ERS Task Force Report. Guidelines for management of adult community-acquired lower respiratory tract infections. European Respiratory Society. Eur Respir J 1998; 11: 986991.

59. Torres A, El Ebiary M. Relevance of Chlamydia pneumoniae in community-acquired respiratory infections. Eur Respir $J$ 1993; 6: 7-8.

60. Kauppinen MT, Saikku P, Kujala P, Herva E, Syrjala H. Clinical picture of community-acquired Chlamydia pneumoniae pneumonia requiring hospital treatment: a comparison between chlamydial and pneumococcal pneumonia. Thorax 1996; 51: 185-189.

61. British Thoracic Society Standards of Care Committee. British Thoracic Society guidelines for the management of community-acquired pneumonia in childhood. Thorax 2002; 57: Suppl. 1, 1-24.

62. Working Group of the South African Thoracic Society. Management of community-acquired pneumonia in adults. $S$ Afr Med J 2002; 92: 647-655.

63. Heffelfinger JD, Dowell SF, Jorgensen JH, et al. Management of community-acquired pneumonia in the era of pneumococcal resistance: a report from the drug-resistant Streptococcus pneumoniae therapeutic working group. Arch Intern Med 2000; 160: 1399-1408.

64. Mandell LA, Marrie TJ, Grossman RF, Chow AW, Hyland RH. Canadian guidelines for the initial management of community-acquired pneumonia: an evidence-based update by the Canadian Infectious Diseases Society and the Canadian Thoracic Society. The Canadian community-acquired pneumonia working group. Clin Infect Dis 2000; 31: 383-421.

65. Principi N, Esposito S, Blasi F, Allegra L. Role of Mycoplasma pneumoniae and Chlamydia pneumoniae in children with community-acquired lower respiratory tract infections. Clin Infect Dis 2001; 32: 1281-1289.

66. Esposito S, Bosis S, Cavagna R, et al. Characteristics of Streptococcus pneumoniae and atypical bacterial infections in children 2-5 years of age with community-acquired pneumonia. Clin Infect Dis 2002; 35: 1345-1352.

67. Dudas V, Hopefl A, Jacobs R, Guglielmo BJ. Antimicrobial selection for hospitalized patients with presumed community-acquired pneumonia: a survey of nonteaching US community hospitals. Ann Pharmacother 2000; 34: 446-452.

68. Gleason PP, Kapoor WN, Stone RA, et al. Medical outcomes and antimicrobial costs with the use of the American Thoracic Society guidelines for outpatients with community-acquired pneumonia. JAMA 1997; 278: 32-39.

69. Mufson MA, Stanek RJ. Bacteremic pneumococcal pneumonia in one American city: a 20-year longitudinal study, 1978-1997. Am J Med 1999; 107: 34S-43S.

70. Plouffe JF. Importance of atypical pathogens of communityacquired pneumonia. Clin Infect Dis 2000; 31: Suppl. 2, S35S39. 
71. Stahl JE, Barza M, DesJardin J, Martin R, Eckman MH. Effect of macrolides as part of initial empiric therapy on length of stay in patients hospitalized with communityacquired pneumonia. Arch Intern Med 1999; 159: 2576-2580.

72. Blasi F, Legnani D, Lombardo VM, et al. Chlamydia pneumoniae infection in acute exacerbations of COPD. Eur Respir J 1993; 6: 19-22.

73. Theegarten D, Mogilevski G, Anhenn O, Stamatis G, Jaeschock R, Morgenroth K. The role of chlamydia in the pathogenesis of pulmonary emphysema. Electron microscopy and immunofluorescence reveal corresponding findings as in atherosclerosis. Virchows Arch 2000; 437: 190193.

74. von Hertzen LC. Chlamydia pneumoniae and its role in chronic obstructive pulmonary disease. Ann Med 1998; 30: 27-37.

75. Blasi F, Damato S, Cosentini R, et al. Chlamydia pneumoniae and chronic bronchitis: association with severity and bacterial clearance following treatment. Thorax 2002; 57: 672676.

76. von Hertzen L, Isoaho R, Leinonen $\mathrm{M}$, et al. Chlamydia pneumoniae antibodies in chronic obstructive pulmonary disease. Int J Epidemiol 1996; 25: 658-664.

77. Blasi F, Cosentini R, Damato S. Chlamydia pneumoniae chronic infection increases the risk of bacterial colonization in chronic bronchitis. Am J Crit Care Respir Med 1997; 155: A592.

78. Murphy TF, Sethi S. Chronic obstructive pulmonary disease: role of bacteria and guide to antibacterial selection in the older patient. Drugs Aging 2002; 19: 761-775.

79. Beaty CD, Grayston JT, Wang SP, Kuo CC, Reto CS, Martin TR. Chlamydia pneumoniae, strain TWAR, infection in patients with chronic obstructive pulmonary disease. $\mathrm{Am}$ Rev Respir Dis 1991; 144: 1408-1410.

80. Miyashita N, Niki Y, Nakajima M, Kawane H, Matsushima T. Chlamydia pneumoniae infection in patients with diffuse panbronchiolitis and COPD. Chest 1998; 114: 969-971.

81. Soler N, Torres A, Ewig S, et al. Bronchial microbial patterns in severe exacerbations of chronic obstructive pulmonary disease (COPD) requiring mechanical ventilation. Am J Respir Crit Care Med 1998; 157: 1498-1505.

82. Mogulkoc N, Karakurt S, Isalska B, et al. Acute purulent exacerbation of chronic obstructive pulmonary disease and Chlamydia pneumoniae infection. Am J Respir Crit Care Med 1999; 160: 349-353.

83. Karnak D, Beng-sun S, Beder S, Kayacan O. Chlamydia pneumoniae infection and acute exacerbation of chronic obstructive pulmonary disease (COPD). Respir Med 2001; 95: 811-816.

84. Seemungal TA, Wedzicha JA, MacCallum PK, Johnston SL, Lambert PA. Chlamydia pneumoniae and COPD exacerbation. Thorax 2002; 57: 1087-1088.

85. Anthonisen NR, Manfreda J, Warren CP, Hershfield ES, Harding GK, Nelson NA. Antibiotic therapy in exacerbations of chronic obstructive pulmonary disease. Ann Intern Med 1987; 106: 196-204.

86. Saint S, Bent S, Vittinghoff E, Grady D. Antibiotics in chronic obstructive pulmonary disease exacerbations. A meta-analysis. JAMA 1995; 273: 957-960.

87. Destache CJ, Dewan N, O'Donohue WJ, Campbell JC, Angelillo VA. Clinical and economic considerations in the treatment of acute exacerbations of chronic bronchitis. J Antimicrob Chemother 1999; 43: Suppl. A, 107-113.

88. Cazzola M, Matera MG. Interrelationship between pharmacokinetics and pharmacodynamics in choosing the appropriate antibiotic and the dosage regimen for treating acute exacerbations of chronic bronchitis. Respir Med 1998; 92: 895-901.

89. Balgos AA. Guidelines for the role of antibiotics in acute exacerbation of chronic bronchitis in the Asia pacific region: report and recommendations of a consensus group. Medical Progress: 1998: 29-37.

90. European study on community-acquired pneumonia committee. Management of adult community-acquired lower respiratory tract infections. Eur Respir Rev 1998; 8: 391-426.

91. Esposito S, Principi N. Asthma in children: are chlamydia or mycoplasma involved? Paediatr Drugs 2001; 3: 159-168.

92. Blasi F, Cosentini R, Tarsia P, Capone P, Allegra L. Atypical pathogens and asthma: can they influence the natural history of the disease? Monaldi Arch Chest Dis 2001; 56: $276-280$.

93. Teichtahl H, Buckmaster N, Pertnikovs E. The incidence of respiratory tract infection in adults requiring hospitalization for asthma. Chest 1997; 112: 591-596.

94. Hardy RD, Jafri HS, Olsen K, et al. Mycoplasma pneumoniae induces chronic respiratory infection, airway hyperreactivity, and pulmonary inflammation: a murine model of infectionassociated chronic reactive airway disease. Infect Immun 2002; 70: 649-654.

95. Daian CM, Wolff AH, Bielory L. The role of atypical organisms in asthma. Allergy Asthma Proc 2000; 21: 107111.

96. Micillo E, Bianco A, Auria D, Mazzarella G, Abbate GF. Respiratory infections and asthma. Allergy 2000; 55: Suppl. $61,42-45$.

97. Cunningham AF, Johnston SL, Julious SA, Lampe FC, Ward ME. Chronic Chlamydia pneumoniae infection and asthma exacerbations in children. Eur Respir J 1998; 11: 345 349 .

98. Hahn DL, McDonald R. Can acute Chlamydia pneumoniae respiratory tract infection initiate chronic asthma? Ann Allergy Asthma Immunol 1998; 81: 339-344.

99. von Hertzen L, Toyryla M, Gimishanov A, et al. Asthma, atopy and Chlamydia pneumoniae antibodies in adults. Clin Exp Allergy 1999; 29: 522-528.

100. Hahn DL, Dodge RW, Golubjatnikov R. Association of Chlamydia pneumoniae (strain TWAR) infection with wheezing, asthmatic bronchitis, and adult-onset asthma. JAMA 1991; 266: 225-230.

101. Emre U, Roblin PM, Gelling M, et al. The association of Chlamydia pneumoniae infection and reactive airway disease in children. Arch Pediatr Adolesc Med 1994; 148: 727-732.

102. Hagiwara K, Ouchi K, Tashiro N, Azuma M, Kobayashi K. An epidemic of a pertussis-like illness caused by Chlamydia pneumoniae. Pediatr Infect Dis J 1999; 18: 271-275.

103. Hallander HO, Gnarpe J, Gnarpe H, Olin P. Bordetella pertussis, Bordetella parapertussis, Mycoplasma pneumoniae, Chlamydia pneumoniae and persistent cough in children. Scand J Infect Dis 1999; 31: 281-286.

104. Wright SW, Edwards KM, Decker MD, Grayston JT, Wang S. Prevalence of positive serology for acute Chlamydia pneumoniae infection in emergency department patients with persistent cough. Acad Emerg Med 1997; 4: 179-183.

105. Isaacs D, Joshi P. Respiratory infections and asthma. Med J Aust 2002; 177: Suppl, S50-S51.

106. Allegra L, Blasi F, Centanni S, et al. Acute exacerbations of asthma in adults: role of Chlamydia pneumoniae infection. Eur Respir J 1994; 7: 2165-2168.

107. Miyashita N, Kubota Y, Nakajima M, Niki Y, Kawane H, Matsushima T. Chlamydia pneumoniae and exacerbations of asthma in adults. Ann Allergy Asthma Immunol 1998; 80: 405-409.

108. Freymuth F, Vabret A, Brouard J, et al. Detection of viral, Chlamydia pneumoniae and Mycoplasma pneumoniae infections in exacerbations of asthma in children. J Clin Virol 1999; 13: 131-139.

109. Lieberman D, Lieberman D, Printz S, et al. Atypical pathogen infection in adults with acute exacerbation of bronchial asthma. Am J Respir Crit Care Med 2003; 167: 406-410.

110. Black PN, Scicchitano R, Jenkins CR, et al. Serological evidence of infection with Chlamydia pneumoniae is related to the severity of asthma. Eur Respir J 2000; 15: 254-259.

111. Martin RJ, Kraft M, Chu HW, Berns EA, Cassell GH. A 
link between chronic asthma and chronic infection. $J$ Allergy Clin Immunol 2001; 107: 595-601.

112. Hahn DL, Bukstein D, Luskin A, Zeitz H. Evidence for Chlamydia pneumoniae infection in steroid-dependent asthma. Ann Allergy Asthma Immunol 1998; 80: 45-49.

113. Cazzola M, Matera MG, Blasi F. Macrolide and occult infection in asthma. Curr Opin Pulm Med 2004; 10: 7-14.

114. Amayasu H, Yoshida S, Ebana S, et al. Clarithromycin suppresses bronchial hyperresponsiveness associated with eosinophilic inflammation in patients with asthma. Ann Allergy Asthma Immunol 2000; 84: 594-598.

115. Ekici A, Ekici M, Erdemoglu AK. Effect of azithromycin on the severity of bronchial hyperresponsiveness in patients with mild asthma. J Asthma 2002; 39: 181-185.

116. Black PN, Blasi F, Jenkins CR, et al. Trial of roxithromycin in subjects with asthma and serological evidence of infection with Chlamydia pneumoniae. Am J Respir Crit Care Med 2001; 164: 536-541.

117. Johnston SL. Is Chlamydia pneumoniae important in asthma? The first controlled trial of therapy leaves the question unanswered. Am J Respir Crit Care Med 2001; 164: 513-514.

118. Kraft M, Cassell GH, Pak J, Martin RJ. Mycoplasma pneumoniae and Chlamydia pneumoniae in asthma: effect of clarithromycin. Chest 2002; 121: 1782-1788.

119. MacLeod CM, Hamid QA, Cameron L, Tremblay C, Brisco W. Anti-inflammatory activity of clarithromycin in adults with chronically inflamed sinus mucosa. Adv Ther 2001; 18: 75-82.

120. Spring PM, Miller RH. Initial report of primary sinusitis caused by an atypical pathogen (Mycobacterium chelonae) in an immunocompetent adult. Ear Nose Throat $J$ 1999; 78: 358-359, 362-364.

121. Milgrim LM, Rubin JS, Rosenstreich DL, Small CB. Sinusitis in human immunodeficiency virus infection: typical and atypical organisms. J Otolaryngol 1994; 23: 450-453.

122. Contopoulos I, Ioannidis JP, Lau J. Acute sinusitis in children: current treatment strategies. Paediatr Drugs 2003; 5: 71-80.

123. Fagnan LJ. Acute sinusitis: a cost-effective approach to diagnosis and treatment. Am Fam Physician 1998; 58: 17951796.

124. Casiano RR Azithromycin, amoxicillin in the treatment of acute maxillary sinusitis. Am J Med 1991; 91: 27S-30S.

125. Clement PA, de Gandt JB. A comparison of the efficacy, tolerability and safety of azithromycin and co-amoxiclav in the treatment of sinusitis in adults. J Int Med Res 1998; 26: $66-75$.

126. Klapan I, Culig J, Oreskovic K, Matrapazovski M, Radosevic S. Azithromycin versus amoxicillin/clavulanate in the treatment of acute sinusitis. Am J Otolaryngol 1999; 20: 7-11.

127. Piccirillo JF, Mager DE, Frisse ME, Brophy RH, Goggin A. Impact of first-line versus second-line antibiotics for the treatment of acute uncomplicated sinusitis. JAMA 2001; 286: $1849-1856$

128. Uhari M, Mantysaari K, Niemela M. A meta-analytic review of the risk factors for acute otitis media. Clin Infect Dis 1996; 22: 1079-1083.

129. Block SL. Causative pathogens, antibiotic resistance and therapeutic considerations in acute otitis media. Pediatr Infect Dis $J$ 1997; 16: 449-456.

130. Jacobs MR, Dagan R, Appelbaum PC, Burch DJ. Prevalence of antimicrobial-resistant pathogens in middle ear fluid: multinational study of 917 children with acute otitis media. Antimicrob Agents Chemother 1998; 42: 589-595.

131. Bluestone CD. Clinical course, complications and sequelae of acute otitis media. Pediatr Infect Dis J 2000; 19: Suppl. 5, S37-S46.

132. Bauchner H, Pelton SI, Klein JO. Parents, physicians, and antibiotic use. Pediatrics 1999; 103: 395-401.

133. Froom J, Culpepper L, Jacobs M, et al. Antimicrobials for acute otitis media? A review from the International Primary Care Network. BMJ 1997; 315: 98-102.

134. Kozyrskyj AL, Hildes-Ripstein GE, Longstaffe SE, et al Treatment of acute otitis media with a shortened course of antibiotics: a meta-analysis. JAMA 1998; 279: 1736-1742.

135. Bisno AL, Gerber MA, Gwaltney JM Jr, Kaplan EL, Schwartz RH. Diagnosis and management of group A streptococcal pharyngitis: a practice guideline. Infectious Diseases Society of America. Clin Infect Dis 1997; 25: 574 583

136. Adam D. Antibacterial therapy in infectious bronchial diseases. Recommendations of the German League for control of respiratory tract diseases. Munch Med Wochenschr 1992; 134: 618-619.

137. Dajani A, Taubert K, Ferrieri P, Peter G, Shulman S. Treatment of acute streptococcal pharyngitis and prevention of rheumatic fever: a statement for health professionals. Committee on rheumatic fever, endocarditis, and Kawasaki disease of the council on cardiovascular disease in the young, the American Heart Association. Pediatrics 1995; 96 : $758-764$. 